tions is unclear. The groups compared may have been too small to obtain statistical significance. These groups were similar in size to those of others, ${ }^{12}$ however, and since the trends were different in men and women this would seem to be an unlikely explanation. Alprenololinduced increases in urate concentration have been shown to return baseline levels within two years despite continuous treatment. ${ }^{2}$ If this decreasing effect of alprenolol on urate is also true for other betablockers, no difference in urate values should be expected between patients treated long term with beta-blockers and those not treated with beta-blockers. In fact, no differences were found in this study, where the patients taking beta-blockers had been treated with such agents for an average of more than four years before the study. Moreover, this study confirmed the positive correlation between urate and triglyceride concentrations, and since triglyceride values correlate negatively with HDL-cholesterol concentrations, the negative correlation between urate and HDL-cholesterol concentrations is not surprising, although the underlying mechanism is unknown. Thus the lack of a difference in the plasma lipid and lipoprotein concentrations between patients on long-term beta-blocker treatment and those not on such treatment may be explained by the observed interrelationships between urate and these lipids and by assuming that propranolol, like alprenolol, has a decreasing effect on triglyceride and HDL-cholesterol concentrations, as well as on urate values.

1 Leren P, Helgeland A, Holme I, Foss PO, Hjermann I, Lund-Larsen PG. Effect of propranolol and prazosin on blood lipids. The Oslo Study. Lancet 1980 ;ii :4-6.

2 Bengtson C. Long-term effect of alprenolol as anti-hypertensive agent. Acta Med Scand 1974; suppl 554:9-14.

${ }^{3}$ Kristensen BØ. HDL-cholesterol, Triglycerides and vascular complications in essential hypertension. Acta Med Scand 1981;suppl 646:31-42.

4 Ames RP, Hill P. Elevation of serum lipid levels during diuretic therapy of hypertension. $\mathrm{Am} \mathcal{F} \mathrm{Med} 1976 ; 61: 748-57$.

${ }^{5}$ Fossati P, Prencipe L, Berti G. Use of 3,5-di-chloro-2-hydroxybensenesulfonic acid/4 aminophenazone chromogenic system in direct enzymatic assay of uric acid in serum and urine. Clin Chem $1980 ; 26$ : $227-31$.

(Accepted 16 April 1981)

Medical Department P, Randers City Hospital, University Hospital of Aarhus, Denmark

BENT $\varnothing$ KRISTENSEN, MD, registrar (now medical registrar, Department of Medicine C, Arhus Kommunehospital DK-8000 Árhus)

\section{Arthritis and arthralgia associated with toxocaral infestation}

Arthritis and arthralgia have been associated with various worm infestations-for example, filariasis ${ }^{1}$ and dracontiasis. ${ }^{2}$ Commonly retinal lesions have been associated with toxocaral infestation, ${ }^{3}$ but encephalitis and disease of the liver, lung, and heart may occur. We report a case of arthritis and arthralgia associated with toxocaral infestation.

\section{Case report}

In April 1977 an 18-year-old woman presented with a seven-day history of blurring of vision in the left eye. She had kept dogs and rabbits as pets for many years. On examination visual acuity was $6 / 6$ on the right and $6 / 24$ on the left. Examination of the left fundus showed an area of new choroiditis and a pigmented scar near the macula. The vitreous was noted to be cloudy. White cell count was $8.3 \times 10^{\circ} / 1$ and erythrocyte sedimentation rate $3 \mathrm{~mm}$ in first hour. No eosinophil count was carried out. A toxoplasma dye test gave negative results. Her symptoms settled with oral prednisolone $30 \mathrm{mg}$ daily and betamethasone eye drops.

In November 1977 she presented with transient swelling and stiffness of the right elbow and left wrist and ankle. On examination limitation of movement and slight swelling of the affected joints were noted. White cell count, erythrocyte sedimentation rate, liver function tests, antistreptolysin $O$ titres, autoantibodies, rheumatoid factor, Wassermann reaction, and toxoplasma dye and haemagglutination tests were all normal. HLA typing was A2, A28, B12, and B14. Her symptoms improved on treatment with benorylate.

Between January 1978 and January 1979 she suffered repeated episodes of choroiditis in the left eye and arthralgia. A toxocaral fluorescence antibody test was performed, which was positive. The eosinophil count was $2 \times 10^{8} / 1$.
She was treated with a 21-day course of diethylcarbamazine citrate ( $3 \mathbf{~ m g} / \mathbf{k g})$. After this her ocular and joint symptoms settled rapidly and oral steroids and non-steroidal anti-inflammatory drugs were tailed off.

\section{Comment}

We are unaware of any other reports of arthritis and arthralgia associated with toxocaral infestation. In visceral larva migrans larvae of Toxocara canis migrate through lymphatic and vascular channels throughout the body. Commonly the liver, lung, heart, and eyes are affected. Presumably joint symptoms might occur from direct joint disease as in dracontiasis. In this case joint aspiration was not possible owing to the transient, flitting nature of her arthritis.

${ }^{1}$ Das GC, Sen SB. Chylous arthritis. Br Med $\mathcal{F} 1968$;ii :27-9.

2 Reddy CRRM, Sivaramappa M. Guinea-worm arthritis of knee joint. Br Med f 1968 ; : :155-6.

${ }^{3}$ Raistrik ER, Dean Hart JC. Adult toxocaral infection with focal retinal lesion. $\mathrm{Br}$ Med $\mathcal{F} 1975$;iii:416.

(Accepted 14 April 1981)

Department of Rheumatology, Leicester Royal Infirmary, Leicester LE1 5WW

D WILLIAMS, BSC, MB, senior house officer in rheumatology (present appointment: senior house officer in general medicine, George Ellio Hospital, Nuneaton)

S ROY, MRCP, consultant physician

\section{Polycythaemia rubra vera and congenital deafness in monozygotic twins}

Polycythaemia rubra vera occurring in families is rare, and we can find no previous report of it in monozygotic twins. The cases we describe provide an interesting parallel with the recent report of primary thrombocythaemia in uniovular twins. ${ }^{1}$

\section{Case reports}

CASE 1

A 49-year-old woman who had been deaf since birth presented in 1954 after an episode of haematemesis and melaena. On examination splenomegaly was noted, and investigation showed haemoglobin concentration $14.4 \mathrm{~g} / \mathrm{dl}$; white cell count $37.2 \times 10^{9} / 1$ with a normal differential; platelet coun $319 \times 10^{9} / 1$, and hypercellular bone marrow. Polycythaemia rubra vera was diagnosed, and she was treated with phosphorus-32 and splenic irradiation.

Over subsequent years she suffered from chronic gastrointestinal blood loss from an undetermined site, with asymptomatic hypochromic microcytic anaemia (haemoglobin concentration $6 \cdot 4-10.0 \mathrm{~g} / \mathrm{dl}$ ) that showed rapid rises to $17.0 \mathrm{~g} / \mathrm{dl}$ and $20.4 \mathrm{~g} / \mathrm{dl}$ after courses of oral iron. In March 1968, with a haemoglobin concentration of $21.3 \mathrm{~g} / \mathrm{dl}$, she suffered a fatal mesenteric vein thrombosis. Her white cell count had remained raised during the whole of the illness.

CASE 2

The twin of the first patient, who was physically identical to her and shared the same blood group (B rhesus positive), presented in January 1980, aged 75 years, with a rash of some months' duration. Skin biopsy showed the histology of eczema, which responded satisfactorily to topical steroids. The tip of the spleen was palpable, and splenomegaly was confirmed by technetium scan.

Investigations showed: haemoglobin $19.3 \mathrm{~g} / \mathrm{dl}$; red cell count $6780 \times 10^{9} / 1$ packed cell volume 0.614 ; white cell count $21.0 \times 10^{\%} / 1(54 \%$ neutrophils, $39 \%$ lymphocytes, $5 \%$ monocytes, $2 \%$ eosinophils); platelet count $235 \times 10^{\circ} / 1$; red cell volume $2020 \mathrm{ml}(48 \mathrm{ml} / \mathrm{kg})$; arterial oxygen pressure $13.1 \mathrm{kPa}$; and neutrophil alkaline phosphatase score 225 (normal range 10-110). Haemoglobin electrophoresis showed a normal pattern and an intravenous pyelogram no abnormality. A bone-marrow aspirate was hypercellular with no other abnormality. The bone-marrow karyotype was $46 \mathrm{xx}$ with no $\mathrm{Ph}^{1}$ chromosome. Like her twin sister, she had been deaf since birth. Audiometry showed hightone loss of inner-ear origin compatible with congenital deafness. She was treated by regular venesection to maintain a packed cell volume below 0.45 . White cell and platelet counts remained unchanged. 


\section{Comment}

One of the patients (case 2) had unequivocal polycythaemia rubra vera. The other was diagnosed and managed at a time when estimations of arterial pressure of oxygen and red cell volume were not freely available, but nevertheless we believe that the diagnosis was firmly established. There are few previous reports of polycythaemia rubra vera occurring in siblings, ${ }^{2-5}$ none of whom were twins. We believe that this report, together with the previous description of primary thrombocythaemia in monozygotic twins, supports the possibility that a genetic factor may play some part in the pathogenesis of myeloproliferative diseases. We can find no reference to any association between polycythaemia rubra vera and deafness and assume the occurrence to be fortuitous.

1 Dodsworth H. Primary thrombocythaemia in monozygotic twins. Br Med $\mathcal{f}$ $1980 ; 280: 1506$.

2 Erf LA. Radioactive phosphorus in the treatment of primary polycythaemia vera. Prog Hematol 1956;1:153-65.

${ }^{3}$ Levin WC, Houston EW, Ritzmann SE. Polycythaemia vera with $\mathbf{P h}^{1}$ chromosomes in two brothers. Blood 1967;30:403-510.

- Modan B. Polycythaemia : a review of epidemiological and clinical aspects. 7 Chronic Dis $1971 ; 18: 605-45$.

s Manoharan A, Garson OM. Familial polycythaemia vera: a study of 3 sisters. Scand f Haematol 1976;17:10-6.

(Accepted 23 April 1981)

Norfolk and Norwich Hospital, Norwich, Norfolk NR1 3SR

G FAIRRIE, MRCP, registrar in dermatology

A J BLACK, MD, MRCPATH, consultant haematologist

A W MCKENZIE, FRCP, consultant dermatologist

\section{Shrapnel presenting with symptoms 62 years after wounding}

Several reports exist of penetrating foreign bodies presenting up to 39 years after the initial injury. ${ }^{1-3}$ We describe a patient who first presented 62 years after being wounded with shrapnel.

\section{Case report}

An 85-year-old man presented in May 1979 with a four-month history of an expanding painful swelling over the left lower chest. Examination showed a large fluctuant abscess with no axillary lymphadenopathy. Radiography disclosed no underlying effusion or pulmonary change, and the only other finding was mild congestive heart failure partially controlled by diuretic treatment. Investigations showed pronounced neutrophil leucocytosis $\left(26.0 \times 10^{9} / 1\right)$, erythrocyte sedimentation rate $17 \mathrm{~mm}$ in first hour, haemoglobin concentration $9.8 \mathrm{~g} / \mathrm{dl}$, and mean corpuscular volume $59 \%$; a blood film showed hypochromia.

Surgical drainage of $30 \mathrm{ml}$ of sterile pus was carried out and a piece of shell shrapnel $10 \times 9 \mathrm{~mm}$ removed. With the benefit of hindsight the shrapnel was visible on the initial chest $x$-ray film. Further questioning elicited that he had received minor shrapnel wounds in 1917 . He had recovered rapidly and returned to the front and had subsequently been captured and spent some months as a prisoner of war. He had had no symptoms after this until he had fallen against his left side in January 1979 and had subsequently complained of increasing pain.

\section{Comment}

The longest recorded interval of a foreign body presenting many years after the initial wounding is 39 years. This was in a woman presenting with a swelling of the lip attributed to a piece of glass that had become embedded after a land-mine explosion in $1940 .{ }^{3}$ A piece of shrapnel that had lodged in the chest wall during D-Day worked its way to the surface 35 years later in a 62 -year-old man. With the removal of the shrapnel the patient lost the ability to forecast rain.

Other unusual late presentations include biliary colic caused by a grenade splinter migrating into the common bile duct 34 years after injury, ${ }^{4}$ choledochoduodenal fistula produced by migration of a bullet 32 years after injury, ${ }^{5}$ and haemorrhagic cyst formation in the region of the thyrohyoid membrane occurring 30 years after a penetrating injury.
We think that the presentation of symptoms 62 years after the original entry in the case described merits recording.

${ }^{1}$ Billman P, Weingard D, Lüttgen F. Migration of a shell splinter into the gallbladder after more than 25 years. Fortschritte auf dem Gabiete der Röntgenstrahlen und der Nuklearmedizin 1977;126:593-5.

${ }^{2}$ Birnmeyer G. Intrathoracic aspiration of a foreign body simulating bronchopneumonia (pulmonary complications resulting from a shell splinter 23 years following injury). HNO 1965;13:81-3.

${ }^{3}$ Davies PJM. Not an accident or emergency? Br Med f 1980;280:651.

${ }^{4}$ Rhombert HP, Judmair G, Bodner E. Grenade splinter causing biliary colic. Lancet 1977 ; : 201 .

${ }^{5}$ Weithofer G, Blazek Z, Warm K, Bloch R. Spontaneous expulsion of a migrating infantry missile impacted in the duodenum and the common bile duct, 32 years after wounding. Endoscopy 1977;9:106-9.

(Accepted 23 April 1981)

Kingston General Hospital, Hull HU3 1UR

JOHN KNOX, MRCP, consultant physician in geriatric medicine ALAN WILKINSON, FRCS, consultant surgeon

\section{Toxic optic neuropathy caused by benoxaprofen}

Benoxaprofen is a recently introduced non-steroidal anti-inflammatory drug with useful analgesic and anti-inflammatory properties in the treatment of rheumatic diseases. It is a member of the proprionic group of acidic anti-inflammatories but appears to vary from other compounds in this group since it has weak prostaglandin synthetase inhibitory activity but more effect on macrophage function. ${ }^{1}$ Phototoxic and photoallergic rashes and onycholysis are well-described adverse reactions, but we report on a patient who developed a partially reversible toxic amblyopia while receiving this drug.

\section{Case report}

A 65-year-old woman underwent aortic and mitral valve replacement in 1975 for valve damage secondary to previous rheumatic fever and was subsequently treated with warfarin sodium. In May 1979 she developed an inflammatory polyarthritis with a strongly positive rheumatoid factor (rheumatoid antibody haemagglutination titre $1 / 320$ ), a raised erythrocyte sedimentation rate, and radiological evidence of joint erosion. In May 1980 she developed an endoscopically proved gastric ulcer and was started on cimetidine in a maintenance dose of $400 \mathrm{mg}$ nightly. In July 1980 benoxaprofen $600 \mathrm{mg}$ nightly was started for her active rheumatoid arthritis, with definite improvement in the degree of pain and synovitis.

On 1 September 1980 she complained of progressive blurring of vision over 10 days unassociated with any ocular discomfort. Acuities were reduced to $6 / 12$ in each eye with a small hypermetropic spectacle correction. She showed a severe red-green colour defect and had bilateral central scotomata to a 15 $\mathrm{mm}$ red target (Bjerrum's scrren). Electroretinography showed normal rod and cone responses and normal dark adaptation pattern. Visual evoked responses to a $50 \mathrm{flash} / \mathrm{min}$ pattern reversal stimulus showed low-amplitude potentials that were grossly delayed $(P 100=185 \mathrm{~ms}$ right and left: normal $108+$ SD $2 \mathrm{~ms}$ ). Benoxaprofen was stopped, and over the next month her vision improved.

By March 1981 visual acuities were $6 / 9$ in each eye. The right visual fleld was full to both at $3 \mathrm{~mm}$ white and $15 \mathrm{~mm}$ red target, but in the left eye there was still a relative central scotoma to a $15 \mathrm{~mm}$ red target. An electroretinogram remained normal and the latency of the $\mathrm{P} 10 \mathrm{C}$ component of the visual evoked response had improved to $138 \mathrm{~ms}$ right and $140 \mathrm{~ms}$ left. The optic discs remained ophthalmoscopically normal.

\section{Comment}

A reversible toxic amblyopia has been described in patients taking ibuprofen, the first of the proprionic subseries to be introduced. ${ }^{2}{ }^{3}$ Larger, prospective studies ${ }^{4}$ have failed to confirm this association, suggesting an idiosyncratic response to the drug.

In our patient the clinical and electrophysiological evidence suggest that the visual deterioration was the result of a toxic optic neuropathy due to benoxaprofen, her other treatment having remained unchanged. Confirmation could have been sought by reintroducing the drug, but this was not ethically justifiable. Although this is the first example of 